Cardiovascular pharmacology

\title{
Maternal hypertension and feto-placental growth restriction is reversed by sildenafil: Evidence of independent effects of circulating nitric oxide levels
}

\author{
Victor Hugo Gonçalves-Rizzi, José Sérgio Possomato-Vieira, Regina Aparecida Nascimento, \\ Mayara Caldeira-Dias, Carlos Alan Dias-Junior \\ Department of Pharmacology, Institute of Biosciences of Botucatu, São Paulo State University (UNESP), Botucatu, Sao Paulo, Brazil
}

\section{A R T I C L E I N F O}

\section{Keywords:}

Hypertension

Pregnancy

Sildenafil citrate

Sodium nitrite

N(G)-nitro-L-arginine methyl ester

Rats

\begin{abstract}
A B S T R A C T
Sildenafil has shown nitric oxide (NO)-independent pleiotropic effects, however the mechanisms involved are unclear. We investigated the protective effects of sildenafil against hypertension in pregnancy and feto-placental growth restriction induced by NO inhibition, and if sodium nitrite-derived NO formation influences sildenafil effects. We evaluated the plasmatic levels of NO metabolites, cyclic guanosine monophosphate (cGMP), oxidative stress and myeloperoxidase, which are involved in endothelial dysfunction during hypertension in pregnancy. Also, we performed in vitro experiments to examine cell viability and NO synthesis in human umbilical vein endothelial cells (HUVECs) cultures incubated with plasma from healthy or hypertensive pregnant rats treated (or not) with both drugs, either alone or in association. Sildenafil blunted hypertension in pregnancy and protected against feto-placental growth restriction induced by NO inhibition and these effects of sildenafil alone were similar to those presented by its association with sodium nitrite. Protective effects of sildenafil were observed even with low plasmatic NO levels and were not followed by increases in cGMP levels. Also, sildenafil, but not sodium nitrite, blunted the increases in myeloperoxidase activity. Both drugs (isolated or in association) presented antioxidant effects. Plasma from hypertensive pregnant rats treated with sildenafil, but not sodium nitrite alone, increased the viability of HUVECs. NO synthesis in HUVECs cultures was increased with plasma from rats treated with both drugs. We conclude that sildenafil effects are not dependent of circulating NO levels in hypertension and feto-placental growth restriction. These findings may reflect a protection against myeloperoxidase and pro-oxidant activation in hypertension in pregnancy.
\end{abstract}

\section{Introduction}

Hypertensive disorders of gestation complicate about $5-10 \%$ of pregnancies, including gestational hypertension that could progress to preeclampsia (Jim and Karumanchi, 2017; Lo et al., 2013). If untreated, these disorders are major causes of maternal and fetal morbidity and mortality (Uzan et al., 2011). Preeclampsia is also associated with intrauterine fetal growth restriction, accounting for $10-15 \%$ of preterm births (Mitani et al., 2009); however, the underlying mechanisms of this disorder are unclear. The initiating event is widely believed to be the impaired spiral artery remodeling that, in turn, leads to a stage of poor placentation with posterior ischemia/hypoxia (Roberts, 2014). Ischemic placenta releases soluble factors into maternal circulation, resulting in the secondary stage of the disorder featured by endothelial dysfunction (Possomato-Vieira and Khalil, 2016).

Physiological blood pressure during pregnancy may rely greatly on the vasodilatory action of nitric oxide (NO) (Leiva et al., 2016). NO also seems to influence the cytotrophoblast invasion and mediates the spiral artery remodeling to allow an adequate supply for the growing fetus (Velicky et al., 2016). In fact, circulating levels of nitrite, a NO metabolite, are increased in normal pregnant women compared to both healthy non-pregnant and preeclamptic women (Cadnapaphornchai et al., 2001). Pregnant rats develop hypertension and feto-placental growth restriction if NO formation is pharmacologically reduced by $\mathrm{N} \omega$-Nitro-L-arginine methyl ester (L-NAME), an agent that effectively inhibits endothelial, neuronal and inducible NO synthases (Ramesar et al., 2010).

Sildenafil is clinically used to treat erectile dysfunction (Hatzimouratidis, 2006). The known mechanism of sildenafil's action is the inhibition of phosphodiesterase type 5 (PDE5), which lengthens the NO-cyclic guanosine $3^{\prime}, 5^{\prime}$-monophosphate (cGMP) signaling by preventing the degradation of cGMP (Francis et al., 2010). Hence, based on

\footnotetext{
* Correspondence to: Department of Pharmacology, Biosciences Institute of Botucatu, Sao Paulo State University, Distrito de Rubiao Junior, Rua Prof. Dr. Antonio Celso Wagner Zanin, S/N, 18 618-689 Botucatu, SP, Brazil.

E-mail address: carlosjunior@ibb.unesp.br (C.A. Dias-Junior).
} 
this canonic mechanism of sildenafil in potentiating NO-induced vasodilation, one may consider that as a NO-dependent drug, sildenafil would have no potential to achieve therapeutic goals, considering there may be reduction of NO in preeclampsia or when the endogenous NO synthesis is reduced by L-NAME in pregnant rats (Motta et al., 2015). However, previous studies showed that sildenafil attenuates hypertension and feto-placental growth restriction in L-NAME-treated rats (Nassar et al., 2012; Ramesar et al., 2010) as well as in hypertensive pregnant mice deficient in endothelial NO synthase (Roberts et al., 2016). Together, these preclinical findings suggest that sildenafil effects may not depend of circulating NO levels (Chrysant and Chrysant, 2012). However, mechanistic studies are needed to explain these sildenafil effects and to determine its potential efficacy in hypertensive disorders of gestation complicated by fetal growth restriction (Trapani et al., 2016), even with reduced levels of NO (Sandrim et al., 2008).

The main hypotheses tested in the present study were that sildenafil, independently of NO levels into maternal circulation, attenuates hypertension-in-pregnancy and feto-placental growth restriction and that these effects could be associated with endothelial cells protection against oxidative stress.

\section{Materials and methods}

\subsection{Animals and experimental protocol}

Wistar rats (200-250 g) were housed in cages at $22 \pm 2{ }^{\circ} \mathrm{C}$ on a 12 $\mathrm{hr}$ light/dark cycle and given free access to water and rat chow. Each female rat was separately mated overnight. Day 1 of pregnancy was defined as the day when spermatozoa were found in a vaginal smear.

On pregnancy day 14, each pregnant rat mother was first placed into a single cage and randomized to one of the eight treatment groups ( $\mathrm{n}=8-10$ per group): Normal Pregnant (NP), Normal Pregnant + Sildenafil $(\mathrm{NP}+\mathrm{S})$, Normal Pregnant + Nitrite $(\mathrm{NP}+\mathrm{N})$, Normal Pregnant + Sildenafil + Nitrite $(\mathrm{NP}+\mathrm{S}+\mathrm{N})$, Hypertensive Pregnancy (HP), Hypertensive Pregnancy + Sildenafil $(\mathrm{HP}+\mathrm{S})$, Hypertensive pregnancy + Nitrite $(\mathrm{HP}+\mathrm{N})$ and Hypertensive Pregnancy + Sildenafil + Nitrite group $(\mathrm{HP}+\mathrm{S}+\mathrm{N})$. In hypertensive pregnant groups (HP groups), rats received intraperitoneal (i.p.) injections of L-NAME (Sigma, St. Louis, MO, \#5751) $60 \mathrm{mg} / \mathrm{kg} /$ daily from 15th - 21st gestational day (Yang et al., 2011). Sildenafil citrate (Pfizer, UK-92480-10) was administered by gavage at a dose of $10 \mathrm{mg} /$ $\mathrm{kg} /$ day from 15th -21 st gestational day (Baijnath et al., 2014). Sodium nitrite was administered by gavage at dosage of $15 \mathrm{mg} / \mathrm{kg} /$ day (Sigma, St. Louis, MO, \#S2252) from 15th - 21st gestational day. The dose of sodium nitrite was chosen with basis on previous studies showing that this dose exerts relevant antihypertensive and antioxidant effects in rats (Gonçalves-Rizzi et al., 2016; Montenegro et al., 2011; Pinheiro et al., 2014, 2015).

Rats were euthanized on gestation-day 21 under overdose of isoflurane followed by exsanguination. Blood samples were collected in lyophilized ethylenediamine tetraacetic acid (EDTA, Vacuntainer Becton-Dickinson, BD, Oxford, UK), immediately centrifuged and plasma was separated and stored at $-80^{\circ} \mathrm{C}$ until use for biochemical analysis.

All procedures for animal experimentation were approved by the Ethics Committee, Biosciences Institute of Botucatu, São Paulo State University (Protocol \#618/2014), which is complied with international guidelines of the European Community for the use of experimental animals.

\subsection{Blood pressure measurements}

Systolic blood pressure ( $\mathrm{mmHg}$ ) was measured on gestational day 14 (baseline with absence of gavage or i.p. injections) and days 16, 18 and 20, before drugs administration, using tail-cuff plethysmography (Insight, Ribeirao Preto, Sao Paulo, Brazil, \# EFF 306). Briefly, all pregnant rats were first acclimated in a quiet room, conditioned and restrained for 5-10 min in a warm box (Insight, Ribeirao Preto, Sao Paulo, Brazil, \# EFF307) to the measurements for 3 days before the pregnancy day 14 (these data were discarded) and then the baseline systolic blood pressure was determined as the average of the cuff inflation-deflation 3-6) cycles by a trained operator on pregnancy day 14 (Gonçalves-Rizzi et al., 2015).

\subsection{Effects on placenta and fetuses}

On gestational day 21, after euthanasia, animals were placed in supine position and cesarean section was performed. The number of viable fetuses, litter size, fetal weight and placental weight were recorded. Viable fetuses were determined as those which showed no macroscopical sign of malformation and could apparently have a normal outcome with the progression of the pregnancy, as previously reported (Ma et al., 2010).

\subsection{Determination of myeloperoxidase activity}

Myeloperoxidase activity was determined by measuring tetramethylbenzidine (TMB) oxidation in an end-point colorimetric assay. For that, $30 \mu \mathrm{l}$ of plasma (1:100) were incubated with $20 \mu \mathrm{l}$ of phosphate buffer and $100 \mu \mathrm{l}$ of liquid substrate system, composed by TMB (Sigma, St. Louis, MO, USA) and hydrogen peroxide $0.04 \%$, at $37{ }^{\circ} \mathrm{C}$ for $10 \mathrm{~min}$, protected from light. After incubation, the reaction was stopped with $100 \mu \mathrm{l}$ of $\mathrm{H}_{2} \mathrm{SO}_{4}(2 \mathrm{~N})$ and the absorbance at $450 \mathrm{~nm}$ with correction to $630 \mathrm{~nm}$ was read with the spectrophotometer (Synergy 4, BIOTEK, Winooski, VT, USA). The results were expressed in Myeloperoxidase activity (U/L) (Suzuki et al., 1983).

\subsection{Measurements of plasma antioxidant capacity}

The trolox equivalent antioxidant capacity (TEAC) was performed as previously described (Erel, 2004). Briefly, a standard curve was stablished using $100 \mu \mathrm{g}$ of Trolox (6-hidroxy-2,5,7,8 - tetramethylchroman-2-carboxylic-acid, Sigma, St. Louis, MO, USA, catalogue\# 238813) in $1 \mathrm{ml}$ of sodium acetate buffer $(0.4 \mathrm{M}$, $\left.\mathrm{C}_{2} \mathrm{H}_{3} \mathrm{NaO}_{2} \cdot 3 \mathrm{H}_{2} \mathrm{O}\right)+$ glacial acetic acid $(0.4 \mathrm{M})$. Firstly, $20 \mu \mathrm{l}$ of plasma samples were added to $200 \mu \mathrm{l}$ of sodium acetate buffer + glacial acetic acid and the absorbance at $660 \mathrm{~nm}$ was read with the spectrophotometer (Synergy 4, BIOTEK, Winooski, VT, USA). Secondly, $20 \mu \mathrm{l}$ of sodium acetate buffer $(0.03 \mathrm{M})$ and glacial acetic acid $(0.03 \mathrm{M})+$ $\mathrm{H}_{2} \mathrm{O}_{2}+$ ABTS (2,2'-azino-bis-3-ethylbenz-thiazolin-6 sulfonic acid, Sigma A 1888) was added to the samples and incubated for $5 \mathrm{~min}$. Finally, a second spectrophotometer read was performed at $660 \mathrm{~nm}$. The second reading values were subtracted from the values found in the first reading and the antioxidant activity of the sample was expressed as mmol of Trolox equivalent/L.

\subsection{Assessment of lipid peroxidation}

Plasma lipid peroxide levels were determined by measuring thiobarbituric acid-reactive substances (TBARS) (Perico et al., 2015). In test tubes, $100 \mu$ of distilled water, $50 \mu \mathrm{l}$ of $8.1 \%$ sodium dodecyl sulfate (SDS), $375 \mu \mathrm{l}$ of $20 \%$ acetic acid $\mathrm{pH} 3.5$, and $375 \mu \mathrm{l}$ of $0.8 \% 2$-thiobarbituric acid (TBA) diluted in $20 \%$ acetic acid were added to $100 \mu \mathrm{l}$ of sample. For the standard curve, the test tubes contained $25 \mu$ lof a malondialdehyde solution of known concentration, $175 \mu \mathrm{l}$ of distilled water, $50 \mu \mathrm{l}$ of $8.1 \%$ sodium dodecyl sulfate, $375 \mu$ of $20 \%$ acetic acid $\mathrm{pH} 3.5$, and $375 \mu \mathrm{l}$ of $0.8 \%$ 2-thiobarbituric acid (TBA) diluted in $20 \%$ acetic acid. The test tubes were incubated in water bath at $95{ }^{\circ} \mathrm{C}$ for $1 \mathrm{~h}$ and centrifuged at $1792 \mathrm{~g}$ for $10 \mathrm{~min}$. A $200 \mu \mathrm{l}$ aliquot of each sample was transferred to a 96 -well plate. The malondialdehyde formed by the sample reacts with the TBA to produce a colorimetric reaction that was measured using a spectrophotometer (Synergy 4, BIOTEK, Winooski, 


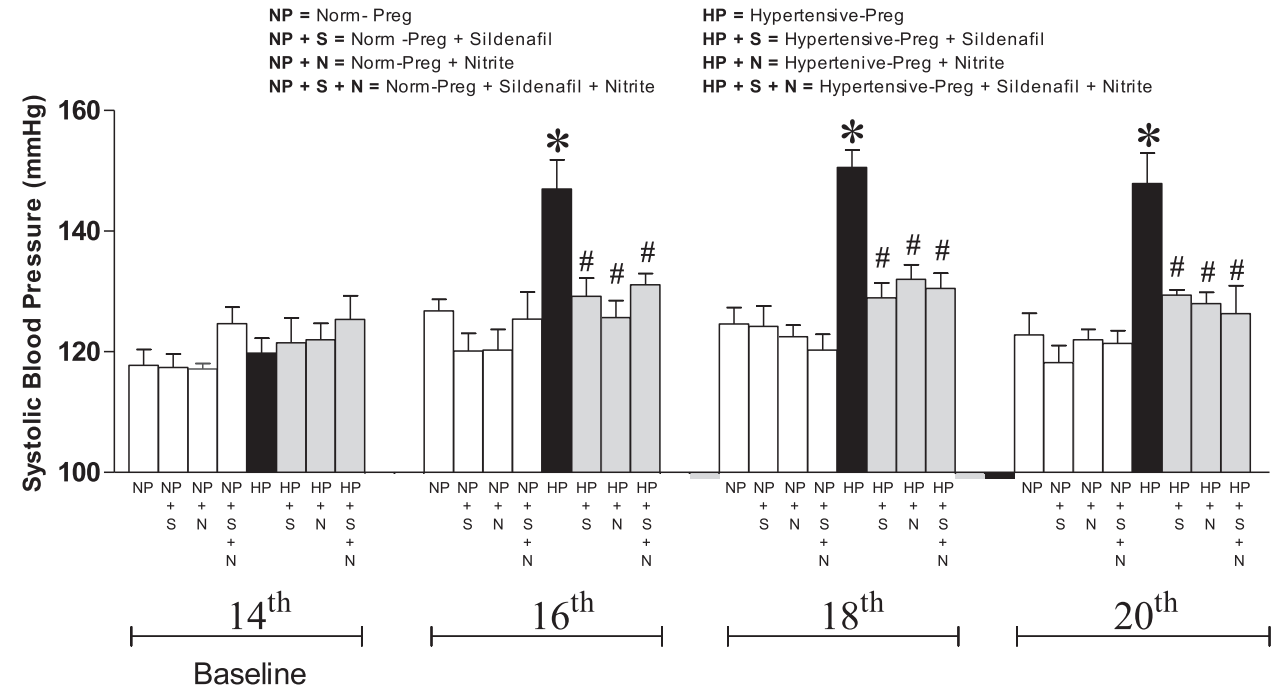

Fig. 1. Systolic blood pressure measured by tail cuff plethysmography on days 14, 16, 18 and 20 of gestation in Normal Pregnant (NP), Normal Pregnant + Sildenafil citrate $(\mathrm{NP}+\mathrm{S})$, Normal Pregnant + Sodium nitrite $(\mathrm{NP}+\mathrm{N})$, Normal Pregnant + sildenafil citrate + sodium nitrite $(\mathrm{NP}+\mathrm{S}+\mathrm{N})$, Hypertensive Pregnancy (HP), Hypertensive pregnancy + Sildenafil citrate $(\mathrm{HP}+\mathrm{S})$, Hypertensive Pregnancy + Sodium nitrite (HP $+\mathrm{N})$, and Hypertensive Pregnancy + sildenafil citrate + sodium nitrite group (HP $+\mathrm{S}+\mathrm{N}$ ). Values represent mean \pm S.E.M. Two-way ANOVA with Bonferroni's correction for multiple comparisons among groups was used to compare measurements on pregnancy days 14, 16, 18 and 20. Significant increases were observed in HP group on pregnancy days 16, 18 and 20. Treatment with sildenafil citrate, sodium nitrite and their association reduced SBP in HP groups. * $\mathrm{P}<0.05$ versus NP group. ${ }^{\#} \mathrm{P}<0.05$ versus $\mathrm{HP}$ group.

Days of gestation

VT, USA) at $532 \mathrm{~nm}$. The lipoperoxide levels were expressed in terms of malondialdehyde $(\mathrm{nmol} / \mathrm{ml})$.

\subsection{Measurement of plasma cyclic guanosine monophosphate (cGMP) concentration}

Arterial blood samples were drawn in tubes containing EDTA and stored at $-80^{\circ} \mathrm{C}$ until the determination of plasmatic cGMP levels using commercial enzyme immunoassay (ELISA) kit (Cayman Chemical no 581021). Assays were performed according to manufacturer's instructions. Plasmatic cGMP levels were expressed in $\mathrm{pmol} / \mathrm{ml}$.

\subsection{Endothelial cell culture and plasma incubation}

The human umbilical vein endothelial cells (HUVECs) were cultured in DMEM medium (Gibco, CA, USA) supplemented with $10 \%(\mathrm{v} / \mathrm{v})$ fetal calf serum (FCS) (Gibco), $50 \mu \mathrm{g} / \mathrm{ml}$ penicillin, $50 \mu \mathrm{g} / \mathrm{ml}$ streptomycin and $0.5 \mu \mathrm{g} / \mathrm{ml}$ amphotericin $\mathrm{B}$ (Gibco) at $37{ }^{\circ} \mathrm{C}$ in $5 \% \mathrm{CO}_{2}$ incubator, as described previously (Roberts et al., 2006). After reaching 80\% confluence, HUVECs were re-suspended in DMEM medium and re-plated in 96-well tissue culture plates (Corning), where they were grown to $80 \%$ confluence for incubation experiments. Then, the medium was removed and cells were washed twice in PBS. Cells were incubated in medium, without FCS, with $10 \%(\mathrm{v} / \mathrm{v})$ plasma from rats treated with saline (NP group), sildenafil (NP $+\mathrm{S}$ group), nitrite (NP $+\mathrm{N}$ group), sildenafil + nitrite (NP $+\mathrm{S}+\mathrm{N}$ group), L-NAME (HP group), L-NAME + sildenafil $(\mathrm{HP}+\mathrm{S}$ group), $\mathrm{L}-\mathrm{NAME}+$ nitrite $(\mathrm{HP}+\mathrm{N})$ and L-NAME + sildenafil + nitrite $(\mathrm{HP}+\mathrm{S}+\mathrm{N})$ for $24 \mathrm{~h}$. The cell supernatant was collected and stored at $-80{ }^{\circ} \mathrm{C}$ to determine the nitrate + nitrite (NOx) concentrations.

\subsection{HUVECs viability assay}

The toxicity for plasma from each pregnant rat was assessed and used to determine the cell viability by using the 3-(4,5-dimethylthiazol2-yl)-2,5-diphenyltetrazolium bromide (MTT) assay as described previously (Mosmann, 1983). Briefly, after $24 \mathrm{~h}$ of plasma incubation in HUVECs (line CRL 2873 obtained from American Type Culture Collection, ATCC, Manassas, VA, USA), the medium was carefully removed and cells were washed twice in PBS. Then, MTT solution $(0.5 \mathrm{mg} / \mathrm{ml}$ PBS) (Sigma-Aldrich) was added and the plate was placed in the incubator $\left(37^{\circ} \mathrm{C}, 5 \% \mathrm{CO}_{2}\right)$. MTT is reduced to blue formazan crystals by metabolically active cells. After $3 \mathrm{~h}$, MTT-formazan crystals were dissolved in DMSO (Sigma-Aldrich) for $10 \mathrm{~min}$ and absorbance was measured at $570 \mathrm{~nm}$ on a multifunctional plate reader (Synergy 4, BIOTEK, Winooski, VT, USA). Viability was compared to control (untreated cells, $100 \%$ viability).

\subsection{Measurement of nitrate + nitrite (NOx) concentrations}

The NOx concentrations were determined in duplicate in plasma and cell supernatant, by Griess reaction, as previously described (DiasJunior et al., 2010). Briefly, $50 \mu \mathrm{l}$ of samples were incubated with the same volume of nitrate reductase buffer $(0.1 \mathrm{M}$ potassium phosphate, $\mathrm{pH} 7.5$, containing $1 \mathrm{mM} \beta$-nicotinamide adenine dinucleotide phosphate and $2 \mathrm{U}$ of nitrate reductase $/ \mathrm{ml}$ ) in individual wells of a 96-well plate. Samples were allowed to incubate overnight at $37^{\circ} \mathrm{C}$ in the dark; $8 \mu \mathrm{l}$ of freshly prepared Griess reagent ( $1 \%$ sulfanilamide, $0.1 \%$ naphthylethylenediamine dihydrochloride in $5 \%$ phosphoric acid) were added to each well and the plate was incubated, for 15 additional min, at room temperature. A standard nitrate curve was obtained by incubating sodium nitrate $(0.2-200 \mu \mathrm{M})$ with the same reductase buffer. The NOx levels in plasma were expressed in $\mu \mathrm{mol} / \mathrm{l}$.

\subsection{Statistical analysis}

Using commercially available statistical software (Graph Pad Prism ${ }^{\circledast}$ 6.0 for Windows, San Diego, CA), a Shapiro-Wilk test was applied to verify normality of data distribution. Systolic blood pressure measurements were submitted to a two-way analysis of variance (ANOVA) followed by Bonferroni's correction for multiple comparisons among groups to compare measurements on pregnancy days 14, 16, 18 and 20, or one-way ANOVA followed by Bonferroni's correction for multiple comparisons were used to compare fetal and placental changes, and oxidative stress analysis, NOx and cGMP levels in plasma, and viability and NOx levels of cells. Statistical significance was considered at $\mathrm{P}<0.05$. All values are expressed as mean \pm S.E.M.

\section{Results}

\subsection{Antihypertensive effects of sildenafil citrate and sodium nitrite in hypertensive pregnant rats}

Baselines systolic blood pressures were similar in all experimental groups 116-125 $\pm 4 \mathrm{mmHg}$ ) on day 14 of gestation (P > 0.05, Fig. 1). Pregnant rats from NP $+\mathrm{S}, \mathrm{NP}+\mathrm{N}$ and NP $+\mathrm{S}+\mathrm{N}$ groups showed no significant changes in systolic blood pressure values throughout the study period, on days 16,18 and 20 of gestation (NP + S, $120 \pm 3$; 

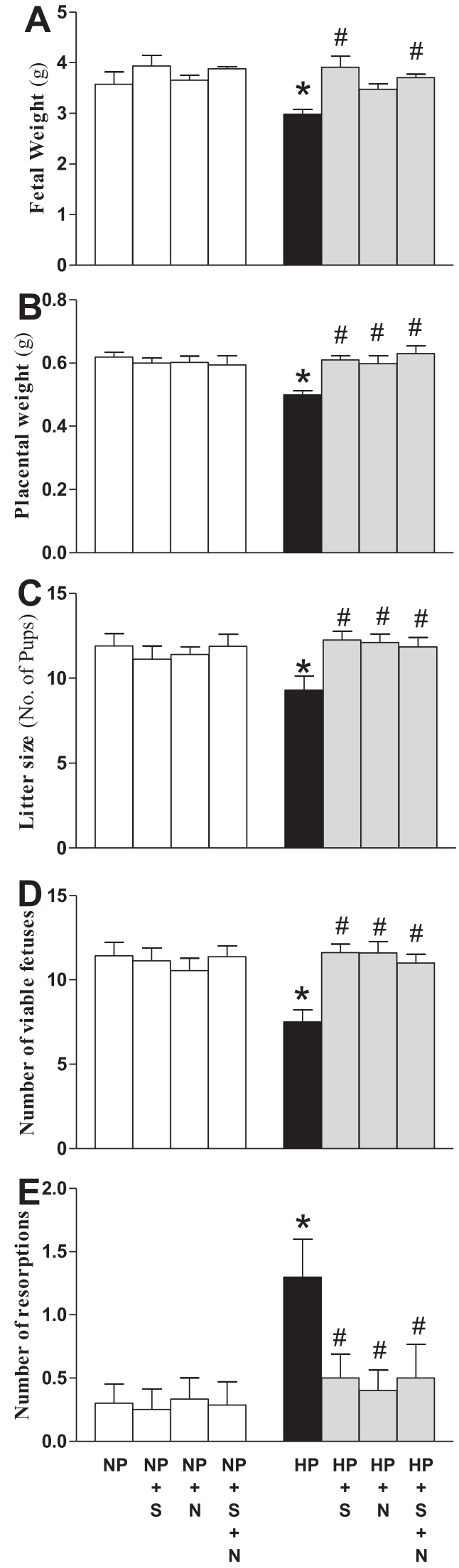

Fig. 2. Fetal and placental parameters were recorded on gestational-day 21: Fetal weight (A), placental weight (B), litter size (C), number of viable fetuses (D) and number of resorptions (E) in Normal Pregnant (NP), Normal Pregnant + Sildenafil citrate (NP + S), Normal Pregnant + Sodium nitrite $(\mathrm{NP}+\mathrm{N})$, Normal Pregnant + sildenafil citrate + sodium nitrite $(\mathrm{NP}+\mathrm{S}+\mathrm{N})$, Hypertensive Pregnancy (HP), Hypertensive pregnancy + Sildenafil citrate $(\mathrm{HP}+\mathrm{S})$, Hypertensive Pregnancy + Sodium nitrite $(\mathrm{HP}+\mathrm{N})$, and Hypertensive Pregnancy + sildenafil citrate + sodium nitrite group $(\mathrm{HP}+\mathrm{S}+\mathrm{N})$. Values represent mean \pm S.E.M. One-way ANOVA followed by Bonferroni's correction for multiple comparisons were used to compare measurements among eight groups. ${ }^{*} \mathrm{P}<0.05$ versus NP group. ${ }^{\#} \mathrm{P}<0.05$ versus HP group.

$124 \pm 3$ and $118 \pm 2.8 \mathrm{mmHg} ; \mathrm{NP}+\mathrm{N}, 120 \pm 3 ; 122 \pm 1.8$ and $122 \pm 1.7 \mathrm{mmHg} ; \mathrm{NP}+\mathrm{S}+\mathrm{N}, 125 \pm 4.5 ; 120 \pm 2.6$ and $121 \pm 2 \mathrm{mmHg}$; $>>0.05$, Fig. 1). However, pregnant rats that received L-NAME presented elevated systolic blood pressure values on days 16, 18 and 20 of gestation (HP group, $145 \pm 5 ; 149 \pm 3$ and $146 \pm 4 \mathrm{mmHg}$, respectively, ${ }^{\mathrm{P}}<0.05$, Fig. 1). However, the pregnant rats that received L-NAME and treated with sildenafil citrate (HP $+\mathrm{S}$ group, $129 \pm 3 ; 128 \pm 2.3 ; 129 \pm 1 \mathrm{mmHg}$ ), sodium nitrite (HP $+\mathrm{N}$ group, $126 \pm 3$; $131 \pm 3 ; 127 \pm 2 \mathrm{mmHg}$ ), and their combination (HP $+\mathrm{S}+\mathrm{N}$ group, $131 \pm 2 ; 130 \pm 2.5 ; 123 \pm 5 \mathrm{mmHg}$ ) showed significant and similar lower systolic blood pressure values on days 16, 18 and 20 of gestation when compared to HP group (145 \pm 5 ; $149 \pm 3$ and $146 \pm 4 \mathrm{mmHg}$, respectively, ${ }^{\#} \mathrm{P}<0.05$, Fig. 1).

\subsection{Sildenafil citrate, but not sodium nitrite, reversed fetal growth restriction}

The fetal weight was significantly lower in HP group $(2.9 \pm 0.08 \mathrm{~g})$ when compared to normal pregnant groups: NP; NP $+\mathrm{S}$; NP $+\mathrm{N}$ and $\mathrm{NP}+\mathrm{S}+\mathrm{N}(3.6 \pm 0.2 ; 3.9 \pm 0.2 ; 3.6 \pm 0.08$ and $3.8 \pm 0.04 \mathrm{~g}$, respectively, " $\mathrm{P}<0.05$, Fig. $2 \mathrm{~A}$ ). Sildenafil reversed fetal growth restriction in HP $+\mathrm{S}$ group $(3.9 \pm 0.2 \mathrm{~g})$ and in $\mathrm{HP}+\mathrm{S}+\mathrm{N}$ group $\left(3.7 \pm 0.06 \mathrm{~g},{ }^{\#} \mathrm{P}<0.05\right.$, Fig. $\left.2 \mathrm{~A}\right)$. However, sodium nitrite alone showed no significant changes in fetal weight $(\mathrm{HP}+\mathrm{N}$ group, $3.4 \pm 0.1 \mathrm{~g} ; \mathrm{P}>0.05$, Fig. $2 \mathrm{~A}$ ).

Placental weight was significantly lower in HP group $(0.49 \pm 0.01 \mathrm{~g})$ when compared to normal pregnant groups: NP; NP + $\mathrm{S} ; \mathrm{NP}+\mathrm{N}$ and $\mathrm{NP}+\mathrm{S}+\mathrm{N}(0.61 \pm 0.02 ; 0.60 \pm 0.01 ; 0.60 \pm 0.01$ and $0.59 \pm 0.02 \mathrm{~g}$, respectively, ${ }^{*} \mathrm{P}<0.05$, Fig. 2B). However, treatment with sildenafil citrate $(\mathrm{HP}+\mathrm{S})$, sodium nitrite $(\mathrm{HP}+\mathrm{N})$, and their combination ( $\mathrm{HP}+\mathrm{S}+\mathrm{N}$ ) reversed placental growth restriction $\left(0.61 \pm 0.01 ; 0.59 \pm 0.03\right.$; and $0.63 \pm 0.02$ g, respectively, ${ }^{\#} \mathrm{P}<0.05$, Fig. 2B).

Number of pups (litter size) was significantly lower in HP group $(9.3 \pm 0.7)$ when compared to normal pregnant groups: NP; NP $+S$; $\mathrm{NP}+\mathrm{N}$ and $\mathrm{NP}+\mathrm{S}+\mathrm{N}(11.9 \pm 1 ; 11.1 \pm 0.6 ; 11.4 \pm 0.6$; and $11.8 \pm 0.5$, respectively, ${ }^{*} \mathrm{P}<0.05$, Fig. $2 \mathrm{C}$ ). Sildenafil citrate (HP $+\mathrm{S}$, $12.2 \pm 0.5)$, sodium nitrite (HP $+\mathrm{N}, 12.1 \pm 0.5)$ and their combination $(\mathrm{HP}+\mathrm{S}+\mathrm{N}, 11.8 \pm 0.5)$ improved litter size $\left({ }^{\#} \mathrm{P}<0.05\right.$, Fig. 2C).

Lower numbers of viable fetuses (Fig. 2D) with higher number of reabsorbed fetuses (Fig. 2E) were found only in HP group (7 \pm 0.7 and $1.3 \pm 0.29$, respectively) when compared to normal pregnant groups: $\mathrm{NP}(11 \pm 1.0$ and $0.30 \pm 0.15), \mathrm{NP}+\mathrm{S}(11.3 \pm 0.7$ and $0.25 \pm 0.16)$; $\mathrm{NP}+\mathrm{N}(10.5 \pm 0.7$ and $0.33 \pm 0.13)$ and $\mathrm{NP}+\mathrm{S}+\mathrm{N}(11.3 \pm 0.6$ and $0.28 \pm 0.18,{ }^{*} \mathrm{P}<0.05$, Fig. $2 \mathrm{D}$ and $\mathrm{E}$, respectively). The treatment with sildenafil, nitrite and their combination increased viable fetuses and concomitantly reduced number of reabsorbed fetuses in HP $+\mathrm{S}$ $(11.6 \pm 0.4$ and $0.5 \pm 0.18), \mathrm{HP}+\mathrm{N}(11.6 \pm 0.6$ and $0.4 \pm 0.16)$ and $\mathrm{HP}+\mathrm{S}+\mathrm{N}(11 \pm 0.5$ and $0.5 \pm 0.26),{ }^{\#} \mathrm{P}<0.05$, Fig. $2 \mathrm{D}$ and $\mathrm{E}$, respectively). 

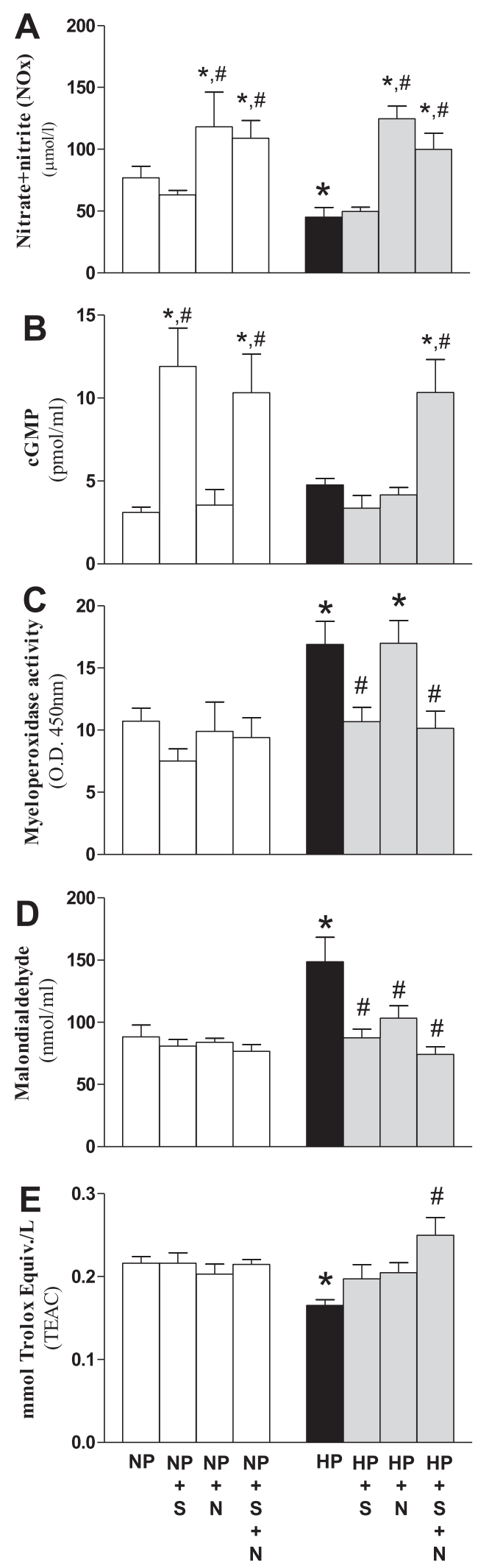

3.3. Sodium nitrite, but not sildenafil citrate, increases plasmatic NOx levels in normotensive and hypertensive pregnant rats

L-NAME treatment significantly reduced NO bioavailability, which was evaluated by measuring plasmatic NOx concentrations in HP group
Fig. 3. Plasmatic NOx levels (A), plasmatic cGMP levels (B), myeloperoxidase activity in plasma (C), malondialdehyde levels in plasma (D), plasma antioxidant capacity (TEAC, E) in Normal Pregnant (NP), Normal Pregnant + Sildenafil citrate $(\mathrm{NP}+\mathrm{S})$, Normal Pregnant + Sodium nitrite $(\mathrm{NP}+\mathrm{N})$, Normal Pregnant + sildenafil citrate + sodium nitrite $(\mathrm{NP}+\mathrm{S}+\mathrm{N})$, Hypertensive Pregnancy (HP), Hypertensive pregnancy + Sildenafil citrate $(\mathrm{HP}+\mathrm{S})$, Hypertensive Pregnancy + Sodium nitrite $(\mathrm{HP}+\mathrm{N})$, and Hypertensive Pregnancy + sildenafil citrate + sodium nitrite group $(\mathrm{HP}+\mathrm{S}+\mathrm{N})$. Values represent mean \pm S.E.M. One-way ANOVA followed by Bonferroni's correction for multiple comparisons were used to compare measurements among eight groups. ${ }^{*} \mathrm{P}<0.05$ versus NP group. ${ }^{\#} \mathrm{P}<0.05$ versus HP group.

(45 $\pm 7 \mu \mathrm{mol} / \mathrm{l})$ compared to those found in NP group (76 $\pm 9 \mu \mathrm{mol} / \mathrm{l}$, ${ }^{*} \mathrm{P}<0.05$, Fig. 3A). As expected, pregnant rats that received (or not) $\mathrm{L}$ NAME and treated with sodium nitrite showed increases in NO bioavailability (NP + N group, $118 \pm 27 ; \mathrm{NP}+\mathrm{S}+\mathrm{N}$ group, $108 \pm 14 ; \mathrm{HP}$ $+\mathrm{N}$ group, $124 \pm 10 ; \mathrm{HP}+\mathrm{S}+\mathrm{N}$ group, $100 \pm 12 \mu \mathrm{mol} / \mathrm{l} ;$; , \# $\mathrm{P}<0.05$, Fig. 3A). However, pregnant rats treated with sildenafil showed no changes in NOx concentrations (NP + S group, $63 \pm 3.7$; HP $+\mathrm{S}$ group, $50 \pm 3.5 \mu \mathrm{mol} / \mathrm{l}$; Fig. $3 \mathrm{~A})$.

3.4. Sildenafil citrate (or sodium nitrite) alone did not increase plasmatic cGMP levels in hypertensive pregnant rats

Similar plasmatic cGMP levels were found in NP group (3.1 \pm 0.32 $\mathrm{pmol} / \mathrm{ml}$ ) and $\mathrm{NP}+\mathrm{N}$ group $(3.5 \pm 0.9 \mathrm{pmol} / \mathrm{ml})$ and HP group $(4.7 \pm 0.39 \mathrm{pmol} / \mathrm{ml})$. As expected, normal pregnant rats treated with sildenafil alone (or in association with nitrite) presented higher plasmatic cGMP levels (NP + S, $11.9 \pm 2.3$; NP + S + N, $10.3 \pm 2.3$ pmol/ $\mathrm{ml}$, respectively) compared to $\mathrm{NP}$ and $\mathrm{HP}$ groups $(*$ \# $\mathrm{P}<0.05$, Fig. 3B). However, pregnant rats that received L-NAME and treated with sildenafil (or nitrite) alone presented no changes in plasmatic cGMP levels (HP $+\mathrm{S}$ group, $3.3 \pm 0.7 ; \mathrm{HP}+\mathrm{N}$ group, $4.1 \pm 0.45$ $\mathrm{pmol} / \mathrm{ml}$, respectively) compared to NP and HP groups. The sildenafil in association with nitrite presented higher plasmatic cGMP levels (HP $+\mathrm{S}+\mathrm{N}$ group, $10.3 \pm 1.9 \mathrm{pmol} / \mathrm{ml}$ ) compared to NP and HP groups (*, \# $\mathrm{P}<0.05$, Fig. 3B).

\subsection{Sildenafil citrate, but not sodium nitrite, decreases myeloperoxidase activity}

$\mathrm{HP}$ and HP $+\mathrm{N}$ groups presented increases in myeloperoxidase activity $\left(16.9 \pm 1.8\right.$ and $17 \pm 1.8 \mathrm{U} / \mathrm{L}$, respectively, ${ }^{*} \mathrm{P}<0.05$, Fig. 3C) when compared to normal pregnant groups: NP $(10 \pm 1 \mathrm{U} / \mathrm{L})$, $\mathrm{NP}+\mathrm{S}(7.5 \pm 0.9 \mathrm{U} / \mathrm{L}), \mathrm{NP}+\mathrm{N}(9.9 \pm 2.3 \mathrm{U} / \mathrm{L})$, and NP + S + N $(9.4 \pm 1.5 \mathrm{U} / \mathrm{L})$. Interestingly, sildenafil prevented increases in myeloperoxidase activity (HP $+\mathrm{S}$ group, $10.6 \pm 1.1 \mathrm{U} / \mathrm{L}$; HP $+\mathrm{S}+\mathrm{N}$ group, $10.1 \pm 1.3 \mathrm{U} / \mathrm{L}$, respectively, ${ }^{\#} \mathrm{P}<0.05$, Fig. $3 \mathrm{C}$ ).

\subsection{Sildenafil citrate and sodium nitrite reduce lipid peroxides levels in hypertensive pregnant rats}

To evaluate the effects of sodium nitrite and sildenafil citrate on hypertension-in-pregnancy-induced increase in oxidative stress, lipid peroxides levels were evaluated by thiobarbituric acid-reactive substances (expressed in malondialdehyde levels). Lipid peroxidation in HP group was elevated (148 $\pm 19 \mathrm{nmol} / \mathrm{ml})$ compared to normal pregnant groups: $\mathrm{NP}(88 \pm 9 \mathrm{nmol} / \mathrm{ml}), \mathrm{NP}+\mathrm{S}(80 \pm 5 \mathrm{nmol} / \mathrm{ml}), \mathrm{NP}+\mathrm{N}$ $(83 \pm 3 \mathrm{nmol} / \mathrm{ml})$, and $\mathrm{NP}+\mathrm{S}+\mathrm{N}(76 \pm 5 \mathrm{nmol} / \mathrm{ml}$, $* \mathrm{P}<0.05$, Fig. 3D). The treatment with sildenafil citrate, sodium nitrite and their combination prevented the increases in lipid peroxidation (HP $+\mathrm{S}$ group, $87 \pm 7 \mathrm{nmol} / \mathrm{ml}$; HP $+\mathrm{N}$ group, $103 \pm 9 \mathrm{nmol} / \mathrm{ml}$ and $\mathrm{HP}+\mathrm{S}$ $+\mathrm{N}$ group, $74 \pm 6 \mathrm{nmol} / \mathrm{ml},{ }^{\#} \mathrm{P}<0.05$, Fig. 3D).

\subsection{Sildenafil citrate and sodium nitrite improve antioxidant capacity}

Lower antioxidant capacity was found in HP group 

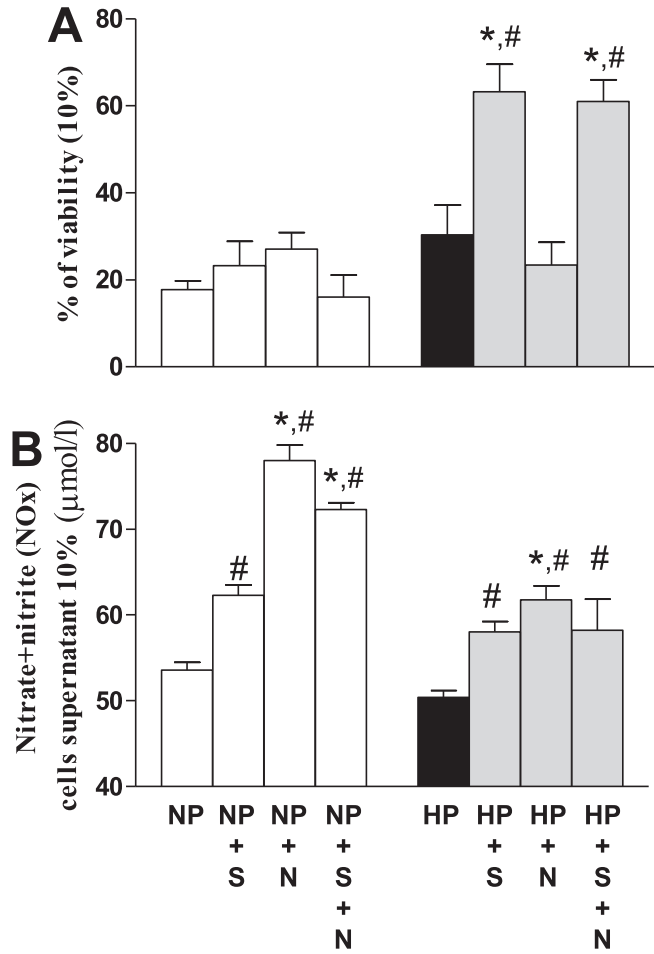

Fig. 4. Cell viability (A) and NOx cell supernatant (B) in Normal Pregnant (NP), Normal Pregnant + Sildenafil citrate $(\mathrm{NP}+\mathrm{S})$, Normal Pregnant + Sodium nitrite $(\mathrm{NP}+\mathrm{N})$, Normal Pregnant + sildenafil citrate + sodium nitrite $(\mathrm{NP}+\mathrm{S}+\mathrm{N})$, Hypertensive Pregnancy (HP), Hypertensive pregnancy + Sildenafil citrate $(\mathrm{HP}+\mathrm{S})$, Hypertensive Pregnancy + Sodium nitrite $(\mathrm{HP}+\mathrm{N})$, and Hypertensive Pregnancy + sildenafil citrate + sodium nitrite group $(\mathrm{HP}+\mathrm{S}+\mathrm{N})$. Values represent mean \pm S.E.M. One-way ANOVA followed by Bonferroni's correction for multiple comparisons were used to compare measurements among eight groups. ${ }^{*} \mathrm{P}<0.05$ versus NP group. ${ }^{\#} \mathrm{P}<0.05$ versus HP group.

$(0.16 \pm 0.006 \mathrm{mmol}$ of Trolox equivalent/L) when compared to normal pregnant groups: NP $(0.21 \pm 0.008 \mathrm{mmol}$ of Trolox equivalent/L) and $\mathrm{NP}+\mathrm{S}(0.21 \pm 0.10 \mathrm{mmol}$ of Trolox equivalent/L) *P $<0.05$, Fig. 3E). Although hypertensive pregnant rats treated with sildenafil alone (HP $+\mathrm{S}$ group, $0.19 \pm 0.10 \mathrm{mmol}$ of Trolox equivalent/L) or sodium nitrite alone (HP $+\mathrm{N}$ group, $0.20 \pm 0.10 \mathrm{mmol}$ of Trolox equivalent/L) showed trends to reverse the reduction of the antioxidant capacity, no statistical differences were observed. However, sildenafil associated with sodium nitrite, surprisingly, significantly increased the antioxidant capacity ( $\mathrm{HP}+\mathrm{S}+\mathrm{N}$ group, $0.25 \pm 0.21 \mathrm{mmol}$ of Trolox equivalent/L, ${ }^{\#} \mathrm{P}<0.05$, Fig. 3E).

3.8. Plasma from hypertensive pregnant rats treated with sildenafil citrate, but not with sodium nitrite, increases endothelial cell viability

The HUVECs showed higher cell viability when incubated with plasma from hypertensive pregnant rats treated with sildenafil citrate (HP $+\mathrm{S}$ group, $58.6 \pm 5 \%$; HP $+\mathrm{S}+\mathrm{N}$ group, $58.1 \pm 5 \%$ ) when compared to all other groups: NP (17 $\pm 2 \%), \mathrm{NP}+\mathrm{S}(23 \pm 5 \%), \mathrm{NP}+$ $\mathrm{N}(27 \pm 3 \%), \mathrm{NP}+\mathrm{S}+\mathrm{N}(16 \pm 5 \%), \mathrm{HP}(30 \pm 7 \%)$ and $\mathrm{HP}+\mathrm{N}$ $(23 \pm 5 \%),{ }^{*},{ }^{*} \mathrm{P}<0.05$, Fig. 4A). However, hypertensive pregnant rats treated with sodium nitrite alone (HP $+\mathrm{N}$ group) showed no changes in HUVECs viability ( $\mathrm{P}>0.05$, Fig. $4 \mathrm{~A})$.

3.9. Plasma from normotensive and hypertensive pregnant rats treated with sildenafil citrate and sodium nitrite (alone or in association) increase NO production in endothelial cells

The HUVECs incubated with plasma from normal pregnant rats treated with sodium nitrite showed higher NOx concentrations in cells supernatants $(\mathrm{NP}+\mathrm{N}$ group, $78 \pm 1 ; \mathrm{NP}+\mathrm{S}+\mathrm{N}$ group, $72 \pm 0.7 \mu \mathrm{mol} / \mathrm{l}$ ) compared to NP group ( $54 \pm 0.9 \mu \mathrm{mol} / \mathrm{l}$, *P $<0.05$, Fig. 4B). Interestingly, HUVECs incubated with plasma from normal pregnant rats treated with sildenafil also showed significant increases in NOx concentrations in cells supernatants (NP $+\mathrm{S}$ group, $62 \pm 1 \mu \mathrm{mol} /$ 1) compared to NP group ( $53 \pm 0.9 \mu \mathrm{mol} / 1$, *P $<0.05$, Fig. 4B). Also, HUVECs incubated with plasma from hypertensive pregnant rats treated with sildenafil, sodium nitrite isolated or in combination presented increases in the NOx concentrations in cells supernatants (HP + $\mathrm{S}$ group, $58 \pm 1 ; \mathrm{HP}+\mathrm{N}$ group, $61 \pm 1 ; \mathrm{HP}+\mathrm{S}+\mathrm{N}$ group, $60 \pm 3 \mu \mathrm{mol} / \mathrm{l}$ ) when compared to HP group ( $49 \pm 0.7 \mu \mathrm{mol} / \mathrm{l}$, ${ }^{\#} \mathrm{P}<0.05$, Fig. 4B).

\section{Discussion}

The main findings in the present study were that (1) sildenafil attenuated hypertension and feto-placental growth restriction caused by L-NAME in pregnant rats; (2) both maternal and feto-placental beneficial sildenafil effects observed here were not dependent of NO and cGMP bioavailability, because similar sildenafil effects were found in the presence of increased or decreased circulating NO levels caused by sodium nitrite or L-NAME, respectively; and were not dependent of increases in cGMP levels (3) sildenafil (but not sodium nitrite) protected against fetal growth restriction as well as increases in myeloperoxidase activity caused by L-NAME; (4) while both drugs isolated blunted increases in lipid peroxidation and reductions in antioxidant capacity caused by L-NAME, only association enhanced the plasma antioxidant capacity; (5) higher HUVECs viability was found after incubation with plasma from L-NAME-induced hypertensive pregnant rats treated with sildenafil; (6) HUVECs cultures incubated with plasma from healthy or from L-NAME-induced hypertensive pregnant rats treated with both drugs (either isolated or combined) showed higher NO levels in cells supernatants compared with controls.

Studies have shown that reductions in circulating NO levels by pharmacological inhibition of NOS synthesis with L-NAME resulted in maternal hypertension, feto-placental growth restriction and increases in oxidative stress, which are features of hypertension-in-pregnancylike state (Gonçalves-Rizzi et al., 2016; Possomato-Vieira et al., 2016; Ramesar et al., 2010). In the present study, we found that sildenafil treatment resulted in immediate and sustained attenuation of hypertension and, sildenafil, but not sodium nitrite, also protected against fetal growth restriction caused by L-NAME. To expand these findings and to confirm that sildenafil effects may not depend of circulating NO levels, we examined whether sildenafil effects could be enhanced by sodium nitrite, a drug with the capability to increase the circulating NO levels upon L-NAME-induced inhibition of NO synthesis in pregnant (Gonçalves-Rizzi et al., 2016) and male rats (Kanematsu et al., 2008; Montenegro et al., 2014; Pinheiro et al., 2014). In our hands, neither synergistic nor additive effects of sildenafil combined with sodium nitrite were found. Similar effects on blood pressure and on placental growth were found, independently if sildenafil was used isolated or combined with sodium nitrite. Importantly, sildenafil, but not sodium nitrite, reversed fetal growth restriction. Also, while similar circulating NO levels were found in groups treated with sildenafil or saline, sodium nitrite treatment (alone or combined with sildenafil) resulted in significant increases in circulating NO levels. Therefore, these results indicate that sildenafil effects are not dependent of circulating NO levels.

Particularly, sildenafil is known to prolong the effects of NO signaling by inhibiting the breakdown of the second messenger of NO, cGMP. However, NO bioavailability had not been evaluated in previous studies reporting that sildenafil treatment ameliorates the maternal syndrome of hypertension-in-pregnancy and rescues the fetal growth in different animal models, including the reduced uterine perfusion pressure (RUPP) rat model, Dahl salt-sensitive rat, suramin-treated rat and catechol-O-methyl transferase knockout mouse (George et al., 2013; Gillis et al., 2016; Stanley et al., 2012; Turgut et al., 2008). 
Our study accessed the circulating NO and cGMP levels and indicated that maternal and feto-placental protective effects with sildenafil treatment are not dependent of circulating NO and cGMP levels, i.e. sildenafil could present beneficial effects even under NO synthesis inhibition with L-NAME and upon increases of NO bioavailability with sodium nitrite.

In our hands, treatment with sildenafil alone or in combination with nitrite increased plasmatic cGMP levels in normotensive animals, while only combined treatment increased plasmatic cGMP levels in hypertensive animals. As expected, treatment with sildenafil in normotensive animals (NP $+\mathrm{S}$ and $\mathrm{NP}+\mathrm{S}+\mathrm{N}$ groups) increased plasmatic cGMP levels, as this is the canonic mechanism by which sildenafil exerts its effects (Francis et al., 2010; Hatzimouratidis, 2006). However, NO derived from sodium nitrite did not promoted increases in plasmatic cGMP levels (NP $+\mathrm{N}$ and HP $+\mathrm{N}$ groups). We suggest that an increase in activity of cGMP-specific PDE5 in pregnancy (Ni et al., 2004) inhibited increase in cGMP in NP $+\mathrm{N}$ and $\mathrm{HP}+\mathrm{N}$ groups.

Interestingly, beneficial effects of sildenafil alone in hypertensive pregnant rats were not followed by increases in plasmatic cGMP levels ( $\mathrm{HP}+\mathrm{S}$ group), because in the presence of reduced NO bioavailability induced by L-NAME, there may be not sufficient NO to stimulate soluble guanylate cyclase (sGC) and therefore to increase cGMP levels. This supports our overall observation that sildenafil effects are not dependent of circulating NO levels. Moreover, plasmatic cGMP levels were found to be elevated in HP $+\mathrm{S}+\mathrm{N}$ group, suggesting that nitritederived NO stimulated SGC and increased cGMP levels, which remained higher due to PDE5 inhibition by sildenafil citrate. Thus, increases in the signaling of NO-cGMP pathway by nitrite in association with sildenafil may also be involved in the effects observed in $\mathrm{HP}+\mathrm{S}+\mathrm{N}$ group. Taken together, these results show that the combined administration of nitrite and sildenafil is not advantageous compared with sildenafil alone, because sildenafil alone protected against hypertension and fetal growth restriction without increase cGMP levels in HP $+\mathrm{S}$ group, thus, suggesting that sildenafil effects in hypertension in pregnancy were not dependent of NO and cGMP. Thereby, our present results provide preclinical evidences to support the use of sildenafil in women with hypertension-in-pregnancy with features of preeclampsia (Trapani et al., 2016), even though preeclamptic women have shown reduced NO formation compared to healthy pregnant women (Ehsanipoor et al., 2013; Eleuterio et al., 2013; Schiessl et al., 2006; Tranquilli et al., 2004; Wang et al., 2015).

In order to explain the findings with sildenafil, biochemical determinants of oxidative stress were determined, because sildenafil has revealed antioxidant effects (Gillis et al., 2016; Milani et al., 2005; Ozdegirmenci et al., 2011; Semen et al., 2016; Soobryan et al., 2017). However, this potential and beneficial pleiotropic effect of sildenafil, that counteracts the endothelial dysfunction caused by oxidative stress (Chrysant and Chrysant, 2012) needs to be confirmed in hypertensionin-pregnancy. Regarding to oxidative stress, it is believed that under stress conditions, there are elevated levels of myeloperoxidase, increases in lipid peroxidation and concomitant reduction of plasma antioxidant capacity in maternal circulation that may trigger or maintain widespread maternal endothelial dysfunction in hypertensive disorders of gestation (Gupta et al., 2009; Rocha-Penha et al., 2017). Our present results are in line with these suggestions and we also found that sildenafil (but not sodium nitrite) treatment blunted the increases in myeloperoxidase activity. Furthermore, lower lipid peroxidation (assessed by TBARS) concentrations and rescues of antioxidant capacity were found with both drugs (alone or in association). Interestingly, synergic effects were observed in plasma antioxidant capacity when drugs were used in association.

Given the fact that antihypertensive effects of sildenafil were associated with reductions in both myeloperoxidase activity and TBARS concentrations and that sildenafil restored the plasma antioxidant capacity, our data suggest that sildenafil protected the maternal vasculature against the endothelium dysfunction caused by oxidative stress induced by L-NAME. In addition, similar protective effects against lipid peroxidation observed with both drugs (alone and combined) probably resulted in antioxidant mechanisms shared by both drugs, as previously reported (Amaral et al., 2015; Gillis et al., 2016; Guimarães et al., 2013; Montenegro et al., 2011). Therefore, to clarify the pleiotropic effects of sildenafil involving the endothelium protection, experiments in vitro were performed.

We then assessed the cell viability in HUVECs cultures incubated with plasma from healthy or from L-NAME-induced hypertensive pregnant rats without treatment or treated with sildenafil and nitrite (both alone and in association). Interestingly, higher cell viability was found in HUVECs incubated with plasma from L-NAME-induced hypertensive pregnant rats treated with sildenafil alone or combined with nitrite compared with other groups. However, HUVECs incubated with plasma from L-NAME-induced hypertensive pregnant rats treated with sodium nitrite alone presented no increases in HUVECs viability. Therefore, these findings in vitro suggest that sildenafil, but not sodium nitrite, could protect the endothelial cells against the endogenous prooxidants agents present in plasma, allowing pro-proliferative machinery of HUVECs.

We suggest that sildenafil reduced reactive oxygen species production, because we found that myeloperoxidase activity and lipid peroxidation were reduced by sildenafil. Although the mechanism is not completely elucidated, studies have shown that sildenafil has antioxidant effect by increasing activity of antioxidant enzymes such as catalase, glutathione peroxidase and superoxide dismutase (Celik et al., 2014; Perk et al., 2008). In addition, sildenafil reduces the activity of NADPH oxidase and vascular levels of nitrotyrosines (Guimarães et al., 2013).

Increased myeloperoxidase activity has a role in endothelial dysfunction (Rocha-Penha et al., 2017), which is a hallmark of maternal hypertensive syndromes (Roberts, 1998, 2014). An important fact in gestational hypertensive disorders is ischemia/hypoxia (George et al., 2013). During ischemic conditions there is accumulation of neutrophils in the endothelium, in which activated neutrophils release cytotoxic substances that interact with the endothelium and cause tissue damage (Suzuki et al., 1993). In our hands, sildenafil, but not nitrite, reduced myeloperoxidase activity, which is in accordance with previous studies that reported that lower myeloperoxidase activity indicates lower neutrophil activation (Suzuki et al., 1993) and that drugs that reduce myeloperoxidase activity lead to increases in endothelial cell viability (Tian et al., 2017). In line with these reports, reduction of myeloperoxidase activity by sildenafil may be responsible for increasing in endothelial cell viability in our study.

Considering that sildenafil protects the endothelial cells in vivo and in vitro against damages caused by oxidative stress, and that oxidative stress impairs the NO formation by endothelial cells and further aggravates endothelial dysfunction (Förstermann, 2010), we then assessed the NO availability in vitro in cell supernatant of HUVECs incubated with plasma from healthy or from L-NAME-induced hypertensive pregnant rats without treatment or treated with sildenafil and sodium nitrite (alone or combined). The NO levels in supernatant of HUVECs cultures incubated with plasma from pregnant rats treated with both drugs (either alone and combined) were significantly higher compared to respective controls (pregnant rats treated with saline or LNAME).

Taken together, our present results are in accordance with the idea that in vivo sildenafil treatment produces beneficial effects independent of circulating NO levels, while in vitro sildenafil may protect the healthy endothelial cells against possible damages caused by pro-oxidants agents present in plasma, enabling the HUVECs ability to proliferate, and to synthesize and to release NO. Accordingly, antioxidant mechanisms activated by both drugs (sildenafil and sodium nitrite) may reduce the reactive oxygen species in plasma (Amaral et al., 2015; Gillis et al., 2016; Guimarães et al., 2013; Montenegro et al., 2011), preventing the impairment of NO availability caused by oxidative stress. 
Alternatively, other mechanisms have been proposed to explain our present results showing the increases in NO availability in HUVECs incubated with plasma from rats treated with sildenafil. Previous reports have suggested that sildenafil directly triggers a signaling cascade in endothelial cells, through the action of kinases, resulting in the phosphorylation of endothelial NO synthase, which provides NO synthesis (Kukreja et al., 2004). However, it is important to make clear that further studies are needed to clarify the mechanisms responsible by the effects observed with sildenafil in this study.

Based on protective effects on endothelial cells observed here, we suggest that sildenafil can be compared with soluble fms-like tyrosine apheresis (Thadhani et al., 2016) for the treatment of preeclampsia (Villanueva-García et al., 2007). Furthermore, the pleiotropic and beneficial effects of sildenafil (Karasu et al., 2012) could be more advantageous in cost, access and risks than NO donors (Trapani et al., 2016), including sodium nitrite treatment used here, which may results in side effects such as methemoglobinemia-induced hypoxemia (DeVan et al., 2016) and/or in peroxynitrite formation after superoxide reaction with sodium nitrite-derived NO, leading to vasoconstriction instead of vasodilation (Schulz et al., 2011).

Importantly, since the most commonly used antihypertensive drugs have shown to cause systemic vasodilatation, but have no significant clinical effects on increasing placental blood flow and protection of fetal growth, additional trials should be conducted to address the efficacy and safety of sildenafil in hypertensive pregnant women, particularly, the potential therapeutic role of sildenafil in pregnancies complicated by intrauterine growth restriction (Trapani et al., 2016).

\section{Conclusion}

We concluded that sildenafil effects may not be dependent of circulating NO levels in hypertension in pregnancy, because protective sildenafil effects against hypertension and fetal growth restriction were found in the presence of L-NAME and were independently of sodium nitrite-derived NO. Moreover, these same sildenafil effects were not followed by increases in plasmatic cGMP levels. Also, sildenafil may protect endothelial cells against myeloperoxidase and pro-oxidant activations in hypertension in pregnancy, suggesting pleiotropic sildenafil effects. Clinical studies should be carried out to validate the beneficial effects exerted by sildenafil during hypertension in pregnancy associated with fetal growth restriction.

\section{Acknowledgements}

This study was supported by funding from the Fundacao de Amparo a Pesquisa do Estado de Sao Paulo (FAPESP, Brazil) (2016/18.782-3). The following is gratefully acknowledged: Dr Helio Kushima for his cooperation and advice with technician issues.

\section{Conflict of interest}

There are no known conflicts of interest.

\section{References}

Amaral, J.H., Ferreira, G.C., Pinheiro, L.C., Montenegro, M.F., Tanus-Santos, J.E., 2015. Consistent antioxidant and antihypertensive effects of oral sodium nitrite in DOCAsalt hypertension. Redox Biol. 5, 340-346.

Baijnath, S., Soobryan, N., Mackraj, I., Gathiram, P., Moodley, J., 2014. The optimization of a chronic nitric oxide synthase (NOS) inhibition model of pre-eclampsia by evaluating physiological changes. Eur. J. Obstet. Gynecol. Reprod. Biol. 184, 71-75.

Cadnapaphornchai, M.A., Ohara, M., Morris, K.G., Knotek, M., Rogachev, B., Ladtkow, T., Carter, E.P., Schrier, R.W., 2001. Chronic NOS inhibition reverses systemic vasodilation and glomerular hyperfiltration in pregnancy. Am. J. Physiol. Ren. Physiol. 280, 592-598.

Celik, M., Aksoy, A.N., Aksoy, H., Aksoy, Y., Halici, Z., 2014. Sildenafil reduces ischemiareperfusion injury in rat ovary: biochemical and histopathological evaluation. Gynecol. Obstet. Investig. 78, 162-167.

Chrysant, S.G., Chrysant, G.S., 2012. The pleiotropic effects of phosphodiesterase 5 inhibitors on function and safety in patients with cardiovascular disease and hypertension. J. Clin. Hypertens. 14, 644-649.

DeVan, A.E., Johnson, L.C., Brooks, F.A., Evans, T.D., Justice, J.N., Cruickshank-Quinn, C., Reisdorph, N., Bryan, N.S., McQueen, M.B., Santos-Parker, J.R., Chonchol, M.B., Bassett, C.J., Sindler, A.L., Giordano, T., Seals, D.R., 2016. Effects of sodium nitrite supplementation on vascular function and related small metabolite signatures in middle-aged and older adults. J. Appl. Physiol. 120, 416-425 (1985).

Dias-Junior, C.A., Neto-Neves, E.M., Montenegro, M.F., Tanus-Santos, J.E., 2010. Hemodynamic effects of inducible nitric oxide synthase inhibition combined with sildenafil during acute pulmonary embolism. Nitric Oxide 23, 284-288.

Ehsanipoor, R.M., Fortson, W., Fitzmaurice, L.E., Liao, W.X., Wing, D.A., Chen, D.B., Chan, K., 2013. Nitric oxide and carbon monoxide production and metabolism in preeclampsia. Reprod. Sci. 20, 542-548.

Eleuterio, N.M., Palei, A.C., Rangel-Machado, J.S., Tanus-Santos, J.E., Cavalli, R.C., Sandrim, V.C., 2013. Relationship between adiponectin and nitrite in healthy and preeclampsia pregnancies. Clin. Chim. Acta 423, 112-115.

Erel, O., 2004. A novel automated direct measurement method for total antioxidant capacity using a new generation, more stable ABTS radical cation. Clin. Biochem. 37, $277-285$.

Förstermann, U., 2010. Nitric oxide and oxidative stress in vascular disease. Pflug. Arch. 459, 923-939.

Francis, S.H., Busch, J.L., Corbin, J.D., Sibley, D., 2010. cGMP-dependent protein kinases and cGMP phosphodiesterases in nitric oxide and cGMP action. Pharmacol. Rev. 62, 525-563.

George, E.M., Palei, A.C., Dent, E.A., Granger, J.P., 2013. Sildenafil attenuates placental ischemia-induced hypertension. Am. J. Physiol. Regul. Integr. Comp. Physiol. 305, 397-403.

Gillis, E.E., Mooney, J.N., Garrett, M.R., Granger, J.P., Sasser, J.M., 2016. Sildenafil treatment ameliorates the maternal syndrome of preeclampsia and rescues fetal growth in the Dahl Salt Sensitive rat. Hypertension 67, 647-653.

Gonçalves-Rizzi, V.H., Nascimento, R.A., Possomato-Vieira, J.S., Dias-Junior, C.A., 2015 Sodium nitrite prevents both reductions in circulating nitric oxide and hypertension in 7-day lead-treated rats. Basic Clin. Pharmacol. Toxicol. 118, 225-230.

Gonçalves-Rizzi, V.H., Possomato-Vieira, J.S., Sales-Graça, T.U., Nascimento, R.A., DiasJunior, C.A., 2016. Sodium nitrite attenuates hypertension-in-pregnancy and blunts increases in soluble fms-like tyrosine kinase-1 and in vascular endothelial growth factor. Nitric Oxide. 57, 71-78.

Guimarães, D.A., Rizzi, E., Ceron, C.S., Pinheiro, L.C., Gerlach, R.F., Tanus-Santos, J.E., 2013. Atorvastatin and sildenafil lower blood pressure and improve endothelial dysfunction, but only atorvastatin increases vascular stores of nitric oxide in hypertension. Redox Biol. 1, 578-585.

Gupta, S., Aziz, N., Sekhon, L., Agarwal, R., Mansour, G., Li, J., Agarwal, A., 2009. Lipid peroxidation and antioxidant status in preeclampsia: a systematic review. Obstet. Gynecol. Surv. 64, 750-759.

Hatzimouratidis, K., 2006. Sildenafil in the treatment of erectile dysfunction: an overview of the clinical evidence. Clin. Interv. Aging 1, 403-414.

Jim, B., Karumanchi, S.A., 2017. Preeclampsia: pathogenesis, Prevention, and Long-Term Complications. Semin. Nephrol. 37, 386-397.

Kanematsu, Y., Yamaguchi, K., Ohnishi, H., Motobayashi, Y., Ishizawa, K., Izawa, Y., Kawazoe, K., Kondo, S., Kagami, S., Tomita, S., Tsuchiya, K., Tamaki, T., 2008. Dietary doses of nitrite restore circulating nitric oxide level and improve renal injury in L-NAME-induced hypertensive rats. Am. J. Physiol. Ren. Physiol. 295, 1457-1462.

Karasu, E., Kayacan, N., Sadan, G., Dinc, B., 2012. Endothelial dysfunction in the human umbilical artery due to preeclampsia can be prevented by sildenafil. Clin. Exp. Hypertens. 34, 79-85.

Kukreja, R.C., Ockaili, R., Salloum, F., Yin, C., Hawkins, J., Das, A., Xi, L., 2004. Cardioprotection with phosphodiesterase-5 inhibition-a novel preconditioning strategy. J. Mol. Cell. Cardiol. 36, 165-173.

Leiva, A., Fuenzalida, B., Barros, E., Sobrevia, B., Salsoso, R., Sáez, T., Villalobos, R., Silva, L., Chiarello, I., Toledo, F., Gutiérrez, J., Sanhueza, C., Pardo, F., Sobrevia, L., 2016. Nitric oxide is a central common metabolite in vascular dysfunction associated with diseases of human pregnancy. Curr. Vasc. Pharmacol. 14, 237-259.

Lo, J.O., Mission, J.F., Caughey, A.B., 2013. Hypertensive disease of pregnancy and maternal mortality. Curr. Opin. Obstet. Gynecol. 25, 124-132.

Ma, R.Q., Sun, M.N., Yang, Z., 2010. Effects of preeclampsia-like symptoms at early gestational stage on feto-placental outcomes in a mouse model. Chin. Med. J. 123, 707-712.

Milani, E., Nikfar, S., Khorasani, R., Zamani, M.J., Abdollahi, M., 2005. Reduction of diabetes-induced oxidative stress by phosphodiesterase inhibitors in rats. Comp. Biochem. Physiol. C. Toxicol. Pharmacol. 140, 251-255.

Mitani, M., Matsuda, Y., Makino, Y., Akizawa, Y., Ohta, H., 2009. Clinical features of fetal growth restriction complicated later by preeclampsia. J. Obstet. Gynaecol. Res. 35, $882-887$.

Montenegro, M.F., Amaral, J.H., Pinheiro, L.C., Sakamoto, E.K., Ferreira, G.C., Reis, R.I., Marcal, D.M., Pereira, R.P., Tanus-Santos, J.E., 2011. Sodium nitrite downregulates vascular NADPH oxidase and exerts antihypertensive effects in hypertension. Free Radic. Biol. Med. 51, 144-152.

Montenegro, M.F., Pinheiro, L.C., Amaral, J.H., Ferreira, G.C., Portella, R.L., TanusSantos, J.E., 2014. Vascular xanthine oxidoreductase contributes to the antihypertensive effects of sodium nitrite in L-NAME hypertension. Naunyn Schmiede. Arch. Pharmacol. 387, 591-598.

Mosmann, T., 1983. Rapid colorimetric assay for cellular growth and survival: application to proliferation and cytotoxicity assays. J. Immunol. Methods 65, 55-63.

Motta, C., Grosso, C., Zanuzzi, C., Molinero, D., Picco, N., Bellingeri, R., Alustiza, F., Barbeito, C., Vivas, A., Romanini, M.C., 2015. Effect of sildenafil on pre-eclampsialike mouse model induced by L-Name. Reprod. Domest. Anim. 50, 611-616. 
Nassar, A.H., Masrouha, K.Z., Itani, H., Nader, K.A., Usta, I.M., 2012. Effects of sildenafil in $\mathrm{N} \omega$-nitro-L-arginine methylester-induced intrauterine growth restriction in a rat model. Am. J. Perinatol. 29, 429-434.

Ni, X.P., Safani, M., Rishi, R., Baylis, C., Humphreys, M.H., 2004. Increased activity of cGMP-specific phosphodiesterase (PDE5) contributes to resistance to atrial natriuretic peptide natriuresis in the pregnant rat. J. Am. Soc. Nephrol. 15, 1254-1260.

Ozdegirmenci, O., Kucukozkan, T., Akdag, E., Topal, T., Haberal, A., Kayir, H., Oter, S., Akyol, M., Uzbay, T., 2011. Effects of sildenafil and tadalafil on ischemia/reperfusion injury in fetal rat brain. J. Matern. Fetal Neonatal Med. 24, 317-323.

Perico, L.L., Heredia-Vieira, S.C., Beserra, F.P., Cássia, S.R., Weiss, M.B., Resende, F.A., Santos-Ramos, M.A., Bonifácio, B.V., Bauab, T.M., Varanda, E.A., Gobbi, J.I., Rocha, L.R., Vilegas, W., Hiruma-Lima, C.A., 2015. Does the gastroprotective action of a medicinal plant ensure healing effects? An integrative study of the biological effects of Serjaniamarginata Casar. (Sapindaceae) in rats. J. Ethnopharmacol. 172, 312-324.

Perk, H., Armagan, A., Naziroglu, M., Soyupek, S., Hoscan, M.B., Sutcu, R., Ozorak, A., Delibas, N., 2008. Sildenafil citrate as a phosphodiesterase inhibitor has an antioxidante effect in the blood of men. J. Clin. Pharm. Ther. 33, 635-640.

Pinheiro, L.C., Amaral, J.H., Ferreira, G.C., Montenegro, M.F., Oliveira-Paula, G.H., Tanus-Santos, J.E., 2014. The antihypertensive effects of sodium nitrite are not associated with circulating angiotensin converting enzyme inhibition. Nitric Oxide 40, 52-59.

Pinheiro, L.C., Amaral, J.H., Ferreira, G.C., Portella, R.L., Ceron, C.S., Montenegro, M.F., Toledo-Jr, J.C., Tanus-Santos, J.E., 2015. Gastric S-nitrosothiol formation drives the antihypertensive effects of oral sodium nitrite and nitrate in a rat model of renovascular hypertension. Free Radic. Biol. Med. 87, 252-262.

Possomato-Vieira, J.S., Gonçalves-Rizzi, V.H., Graça, T.U., Nascimento, R.A., Dias-Junior, C.A., 2016. Sodium hydrosulfide prevents hypertension and increases in vascula endothelial growth factor and soluble fms-like tyrosine kinase-1 in hypertensive pregnant rats. Naunyn Schmiede. Arch. Pharmacol. 389, 1325-1332.

Possomato-Vieira, J.S., Khalil, R.A., 2016. Mechanisms of endothelial dysfunction in hypertensive pregnancy and preeclampsia. Adv. Pharmacol. 77, 361-431.

Ramesar, S.V., Mackraj, I., Gathiram, P., Moodley, J., 2010. Sildenafil citrate improves fetal outcomes in pregnant, L-NAME treated, Sprague-Dawley rats. Eur. J. Obstet. Gynecol. Reprod. Biol. 149, 22-26.

Roberts, J.M., 1998. Endothelial dysfunction in preeclampsia. Semin. Reprod. Endocrinol. $16,5-15$.

Roberts, L., LaMarca, B.B., Fournier, L., Bain, J., Cockrell, K., Granger, J.P., 2006. Enhanced endothelin synthesis by endothelial cells exposed to sera from pregnant rats with decreased uterine perfusion. Hypertension 47, 615-618.

Roberts, J.M., 2014. Pathophysiology of ischemic placental disease. Semin. Perinatol. 38, 139-145.

Roberts, R.P., Refuerzo, J.S., Ferrari, F., Ontiveros, A.E., Tamayo, E.H., Sibai, B.M., Blackwell, S.C., Longo, M., 2016. Sildenafil treatment in a non-severe hypertensive murine model lowers blood pressure without reducing fetal growth. Am. J. Obstet. Gynecol. 215 (386.e1-e8).

Rocha-Penha, L., Caldeira-Dias, M., Tanus-Santos, J.E., Carvalho-Cavalli, R., Sandrim, V.C., 2017. Myeloperoxidase in hypertensive disorders of pregnancy and its relation of nitric oxide. Hypertension 69, 1173-1180.

Tian, R., Ding, Y., Peng, Y.Y., Lu, N., 2017. Inhibition of myeloperoxidase- and neutrophil-mediated hypochlorous acid formation in vitro and endothelial cell injury by (-)-Epigallocatechin Gallate. J. Agric. Food Chem. 65, 3198-3203.

Sandrim, V.C., Palei, A.C., Metzger, I.F., Gomes, V.A., Cavalli, R.C., Tanus-Santos, J.E., 2008. Nitric oxide formation is inversely related to serum levels of antiangiogenic factors soluble fms-like tyrosine kinase- 1 and soluble endogline in preeclampsia. Hypertension 52, 402-407.

Schiessl, B., Strasburger, C., Bidlingmaier, M., Mylonas, I., Jeschke, U., Kainer, F., Friese, K., 2006. Plasma and urine concentrations of nitrite/nitrate and cyclic Guanosinemonophosphate in intrauterine growth restricted and preeclamptic pregnancies. Arch. Gynecol. Obstet. 274, 150-154.

Schulz, E., Gori, T., Münzel, T., 2011. Oxidative stress and endothelial dysfunction in hypertension. Hypertens. Res. 34, 665-673.

Semen, K., Yelisyeyeva, O., Jarocka-Karpowicz, I., Kaminskyy, D., Solovey, L., Skrzydlewska, E., Yavorskyi, O., 2016. Sildenafil reduces signs of oxidative stress in pulmonary arterial hypertension: evaluation by fatty acid composition, level of hydroxynonenal and heart rate variability. Redox Biol. 7, 48-57.

Soobryan, N., Murugesan, S., Phoswa, W., Gathiram, P., Moodley, J., Mackraj, I., 2017. The effects of sildenafil citrate on uterine angiogenic status and serum inflammatory markers in an L-NAME rat model of pre-eclampsia. Eur. J. Pharmacol. 795, 101-107.

Stanley, J.L., Andersson, I.J., Poudel, R., Rueda-Clausen, C.F., Sibley, C.P., Davidge, S.T. Baker, P.N., 2012. Sildenafil citrate rescues fetal growth in the catechol-O-methyl transferase knockout mouse model. Hypertension 59, 1021-1028.

Suzuki, S., Toledo-Pereyra, L.H., Rodriguez, F.J., Cejalvo, D., 1993. Neutrophil infiltration as an important factor in liver ischemia and reperfusion injury: modulating effects of FK506 and cyclosporine. Transplantation 55, 1265-1272.

Suzuki, K., Ota, H., Sasagawa, S., Sakatani, T., Fujikura, T., 1983. Assay method for myeloperoxidase in human polymorphonuclear leukocytes. Anal. Biochem. 132, 345-352.

Thadhani, R., Hagmann, H., Schaarschmidt, W., Roth, B., Cingoez, T., Karumanchi, S.A., Wenger, J., Lucchesi, K.J., Tamez, H., Lindner, T., Fridman, A., Thome, U., Kribs, A., Danner, M., Hamacher, S., Mallmann, P., Stepan, H., Benzing, T., 2016. Removal of soluble Fms-Like Tyrosine Kinase-1 by dextran sulfate apheresis in preeclampsia. J. Am. Soc. Nephrol. 27, 903-913.

Tranquilli, A.L., Bezzeccheri, V., Giannubilo, S.R., Scagnoli, C., Mazzanti, L., Garzetti, G.G., 2004. Amniotic vascular endothelial growth factor (VEGF) and nitric oxide (NO) in women with subsequent preeclampsia. Eur. J. Obstet. Gynecol. Reprod. Biol. 113, 17-20.

Trapani, A., Gonçalves, L.F., Trapani, T.F., Vieira, S., Pires, M., Pires, M.M., 2016. Perinatal and hemodynamic evaluation of sildenafil citrate for preeclampsia treatment: a randomized controlled trial. Obstet. Gynecol. 128, 253-259.

Turgut, N.H., Temiz, T.K., Bagcivan, I., Turgut, B., Gulturk, S., Karadas, B., 2008. The effect of sildenafil on the altered thoracic aorta smooth muscle responses in rat preeclampsia model. Eur. J. Pharmacol. 589, 180-187.

Uzan, M., Carbonnel, O., Piconne, R., Asmar, J.M., Ayoubi, 2011. Pre-eclampsia: pathophysiology, diagnosis, and management. Vasc. Health Risk Manag. 7, 467-474.

Velicky, P., Knöfler, M., Pollheimer, J., 2016. Function and control of human invasive trophoblast subtypes: intrinsic vs. maternal control. Cell Adhes. Migr. 10, 154-162.

Villanueva-García, D., Mota-Rojas, D., Hernández-González, R., Sánchez-Aparicio, P., Alonso-Spilsbury, M., Trujillo-Ortega, M.E., Necoechea, R.R., Nava-Ocampo, A.A., 2007. A systematic review of experimental and clinical studies of sildenafil citrate for intrauterine growth restriction and pre-term labour. J. Obstet. Gynaecol. 27, 255-259.

Wang, L., Yang, T., Ding, Y., Zhong, Y., Yu, L., Peng, M., 2015. Chemerin plays a protective role by regulating human umbilical vein endothelial cell-induced nitric oxide signaling in preeclampsia. Endocrine 48, 299-308.

Yang, X., Guo, L., Sun, X., Chen, X., Tong, X., 2011. Protective effects of hydrogen-rich saline in preeclampsia rat model. Placenta 32, 681-686. 